\title{
Investigating the Relationship between Pragmatic Language Development and Early Childhood Education: a Correlational- study on a Sample of Saudi Female Preschoolers and Non- preschoolers
}

\author{
Ahmed Mohammed Saleh Alduais ${ }^{1}$, Razan Ahmed Albassam², Afnan AlSantli ${ }^{3}$, \\ Alhanouf Yousef Alhazimi ${ }^{4}$ \\ ${ }^{1}$ (Research Chair of Voice, Swallowing and Communication Disorders, Department of English Language, \\ College of Medicine/ King Saud University KSU, Kingdom of Saudi Arabia KSA) \\ ${ }^{2-4}$ (Speech-Language Pathology and Audiology Department, College of Medical and Applied Sciences/ KSU,
} KSA)

\begin{abstract}
Purpose: To see if pragmatic language development PLD is really associated with early childhood education EChE or vice versa, and if the preschoolers' group will perform pragmatically better than the nonpreschoolers' group due to enrollment in EChE in the Arabic version of the test of pragmatic language TOPL-2. Method: Thirty Saudi female pupils with normal abilities were purposefully selected and divided into two groups where 15 were identified as preschoolers and 15 as non-preschoolers, in the age range of 6-7 and who were attending the $1^{\text {st }}$ grade elementary school level, have taken a screening test that measures pragmatic language ability PLA, namely the Arabic version of the TOPL-2 in a period of 40 minutes for each.

Results and conclusions: Descriptives, frequencies and graphs' statistical analyses were performed to test the difference between the preschoolers and non-preschoolers' achievement in pragmatic using the Arabic test of pragmatic language A-TOPL. The means and standard deviations of the two groups were very close to one another (M: 9.53, SD: 2.29 and M: 8.20, SD: 2.40). Also, the highest percentage in both the preschoolers' and non-preschoolers' groups was under the average's category ( 73.33 for the former and 93.33 for the latter) with only two cases under the superior category and two under above average in the preschoolers' group and four cases under the below average category in the counterpart group. Besides, a Pearson product-moment correlation coefficient was computed to assess the relationship between PLD and EChE. There was a negative correlation between the two variables, $r=0-.610, n=15$, and $p=0.016$. A scatter-plot summarizing this result approved also a zero relationship between the two variables. Overall, there was a negative correlation between $P L D$ and EChE. Enrollment in preschool education does neither affect nor is related to PLD.
\end{abstract}

Keywords: early childhood education, pragmatic language development, test of pragmatic language, Arabic test of pragmatic language A-TOPL, preschoolers, non-preschoolers

\section{Introduction}

Human's language development is undoubtedly one of the piquing matters to scientists in different fields all over the world. Say it another way, in spite of all the reachable findings regarding human language faculty, it is still widely believed that the puzzle of this faculty remains unanswerable if not unreachable.

With reference to Levine and Munsch ${ }^{1}$; Bartolotta and Shulman ${ }^{2}$, child development is generally introduced in terms of different obligatory occurring systematic changes which can be shown schematically as:

\begin{tabular}{|c|c|c|}
\hline$\underset{\downarrow}{\text { Physical development }} \rightarrow$ & $\underset{\downarrow}{\text { Cognitive development }} \rightarrow$ & $\begin{array}{c}\text { Social-emotional development } \\
\downarrow\end{array}$ \\
\hline Biological changes & Thinking and reasoning & Behaviour \\
\hline
\end{tabular}

Due to this, it is assumed that language is an integrated faculty that develops along with the development of the above mentioned types of development. Researchers in different fields related to the scientific study of language introduced the study of the development of language in terms of different aspects. These disagreements and different views of studying child language development can be schematically shown as:
$\underset{\downarrow}{\text { Phonology }}{ }^{1} \rightarrow$
$\underset{\downarrow}{\text { Syntax }} \rightarrow$
$\underset{\downarrow}{\text { Semantics } \rightarrow}$
Pragmatics
Sounds
grammar
meanings of words
rules of language use 
<smiles></smiles>

Pragmatics

\author{
Meaning $\rightarrow$<smiles>C1=CC1</smiles> \\ Semantics
}<smiles>[R14][As]1CC1</smiles>

Syntax and Morphology
Form

Phonology
Phonology ${ }^{3} \rightarrow$

Sounds

and

intonation patterns
Semantics $\rightarrow$

Words and their associated meanings

\author{
Syntax $\rightarrow$ \\ Grammatical
} rule

\author{
Morphology $\rightarrow$ \\ Rules governing use \\ of morphemes
}

\section{Pragmatics}

Speech adjustment and appropriateness $\underset{\downarrow}{\text { Phonology }} \mathrm{y}^{4} \rightarrow$

Sounds of speech

$$
\text { Vocabulary } \rightarrow
$$

Storehouse of meaning of words

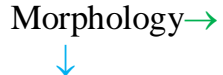

Encoded bits of meaning
Syntax $\rightarrow$

Rules putting words together

The above four models show the main linguistic aspects that child language development should include. The first model is based on [1], the second is based on [3], the third is based on [4], and the fourth is based on [5]. In the last model, the author ${ }^{5}$ maintains that the possibility of adding one more component, namely, pragmatics, is simply possible.

The primary concern of this paper is the development of the pragmatic aspect. Pragmatics is "area of language that embraces the functional use of language in social contexts", [6]. It also "refers to the underpinnings of conversation: how something is said, the intentions of the speaker, the relationship between the participants, and the cultural expectations of the exchange. It is, by its nature, a complicated and elusive part of communication", [6].

Children develop pragmatic language skills in much the same way that they acquire milestones in other areas of development. Pragmatic language skills, such as eye contact and smiling, begin to develop soon after birth. They coincide with and are embedded within regular language development. The following table in Alduais, Al-Hammadi, Shoeib, Almalki, and Alenezi ${ }^{7}$ and Alduais ${ }^{8}, 2012$; show the content of pragmatics as a level of the main components of language.

TABLE 1: Major Communication Skills of Pragmatic Competence

\begin{tabular}{|c|c|c|}
\hline Using language & Changing language & Following rules \\
\hline $\begin{array}{l}\text { Greeting (e.g., Hello) } \\
\text { Informing (e.g., I am going to get } \\
\text { a cookie.) } \\
\text { Demanding (e.g. Give me a } \\
\text { cookie.) } \\
\text { Promising (e.g., I am going to get } \\
\text { you a cookie.) } \\
\text { Requesting(e.g., I would like a } \\
\text { cookie, please.) }\end{array}$ & $\begin{array}{l}\text { Used according to the needs of a } \\
\text { listener or situation } \\
\text { Talking differently to a baby than } \\
\text { to an adult } \\
\text { Giving background information } \\
\text { to an unfamiliar listener } \\
\text { Speaking differently in a } \\
\text { classroom than on a playground }\end{array}$ & $\begin{array}{l}\text { Used for conversations and } \\
\text { storytelling } \\
\text { Takingturns in conversation } \\
\text { Introducing topics of } \\
\text { conversation } \\
\text { Staying on topic } \\
\text { Rephrasing when misunderstood } \\
\text { Using verbal and non-verbal } \\
\text { signals } \\
\text { How close to stand to someone } \\
\text { when speaking } \\
\text { Using facial expressions } \\
\text { Using eye contact }\end{array}$ \\
\hline
\end{tabular}

The researchers, in this paper, claim that pragmatic language development PLD might be associated with early childhood education ECHE.

Farrell and DiBello" defined early childhood education EChE as "a field within education encompassing the knowledge base related to children from birth through age eight (third grade)". Additionally, Polnick ${ }^{10}$ introduced early childhood period in general as "early childhood—from birth to 8 years old—is a time of rapid physical growth, emotional and social development, and the acquisition of the fundamental building blocks for future academic success". Sullivan ${ }^{11}$ also presented EChE as "a period or a stage of human development from two to six years of age, proceeded by infancy...". On the basis of this above given definitions, one can simply realize that EChE is period that a child spends in a school before being enrolled in the formal education.

In fact EChE has many advantages for children or what is referred to usually as preschoolers. These advantages could vary and could be measured at different levels-say cognitive, emotional, social, and linguistic. Reyes and Lopez ${ }^{12}$ discussed the benefits of preschool education which have generally included: 
critical thinking development, social personality, language acquisition and development, and cognitive abilities. Barnett $^{13}$ concludes his paper about preschool education and its lasting effects with that "many different preschool programs have been shown to produce positive effects on children's learning and development, but those effects vary in size and persistence by type of program". A group of researchers ${ }^{14}$ declare that the principal aims of the early childhood programs in the United States US is "to improve the cognitive and social-emotional functioning of preschool children, which, in turn, influences readiness to learn in the school setting". Oppenheim and Macgregor ${ }^{15}$ claim that preschool education or EChE is really an investment project that must be promoted for-all over the US society.

In fact, EChE differs to some extent from one country to another. For instance, in the Kingdom of Saudi Arabia KSA, which is the research environment of this paper, children are welcomed and accepted for enrollment in preschool education starting from age of three years old. The EChE in Saudi Arabia is a government-run program, though a child can join a either a public or a private school. In general, co-education is completely prohibited in all educational levels and system except in the preschool education level ${ }^{16-18}$ (nurseries and kindergartens). Levels of the educational system in KSA can be shown schematically below as:

FIGURE 1: Educational system levels in Saudi Arabia

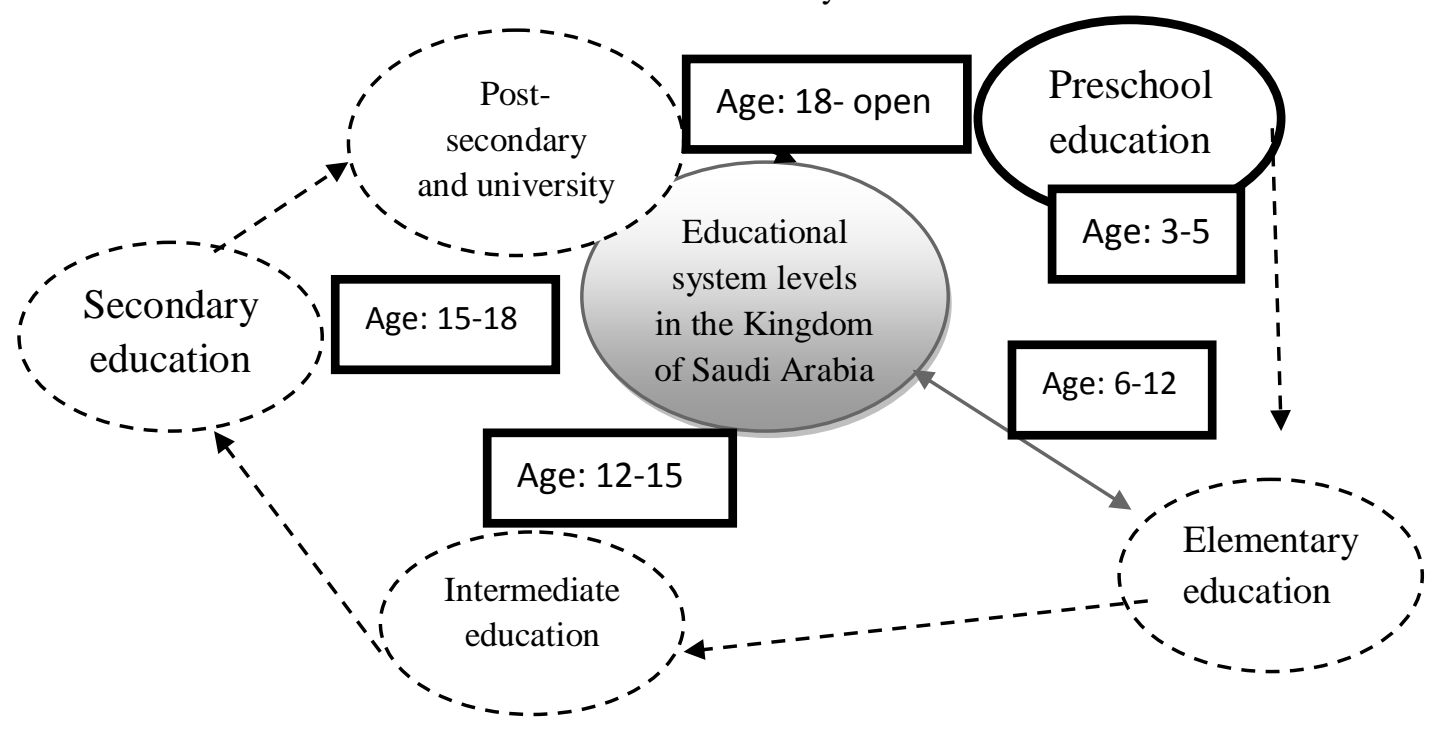

The above figure can be read in a clockwise starting from the preschool education level and ending with post-secondary education level. Each oval circle represents one educational level in KSA and each rectangle represents the possible age for entering and completing each indicated level. The shadowed double arrow shows that the compulsory clockwise movement of educational processes and levels that each pupil and student should undergo must start from this level (elementary) and ends with either secondary or post-secondary according to the learner's ambitions. Again the oval circle coloured in black shows that this educational level (preschool) is optional and not obligatory for being accepted to enroll in the rest of the levels. The number of the opened nurseries and kindergartens schools in $\mathrm{KSA}^{19}$ as shown in the adapted below given table is quite large, but the vital point is whether these opened preschools contribute in advancing the children's level linguistically, cognitively, socially, emotionally, and morally!

TABLE 2: General statistics on early childhood education in KSA, academic year 2010-2011

\begin{tabular}{|c|c|c|c|c|c|c|c|c|c|}
\hline Stage & gender & $\begin{array}{c}\text { Schoo } \\
\text { ls }\end{array}$ & $\begin{array}{c}\text { Class- } \\
\text { rooms }\end{array}$ & \multicolumn{2}{|c|}{ Students } & \multicolumn{2}{|c|}{ Academic staff } & \multicolumn{2}{c|}{$\begin{array}{c}\text { Administrative } \\
\text { staff }\end{array}$} \\
\cline { 5 - 9 } & & & Total & Saudis & Total & Saudis & Total & Saudis \\
\hline $\begin{array}{c}\text { Kindergarte } \\
\mathrm{n}\end{array}$ & $\begin{array}{c}\text { Boys and } \\
\text { girls }\end{array}$ & 1,667 & 6,617 & 117,653 & 109,236 & 11,431 & 10,910 & 2.247 & 2,165 \\
\hline
\end{tabular}

Last but not least and relation to EChE in KSA, it is worth to mention the main goals of this educational level so that it can be incorporated within the investigated issued in this paper. According to [16], the main objectives of this educational level are "nurturing the instincts of the children..., familiarizing the children with school atmosphere and preparing them for school life, teaching the children easy fundamentals 
that suit their age, encouraging the children's imaginative thinking, and protecting them against dangers". Besides, Alshaer ${ }^{17}$ indicated that EChE which stands for "education from birth up to enrollment in primary school" is achieved through the following means [levels] which can be shown schematically as:

FIGURE 2: Early childhood education levels in Saudi Arabia

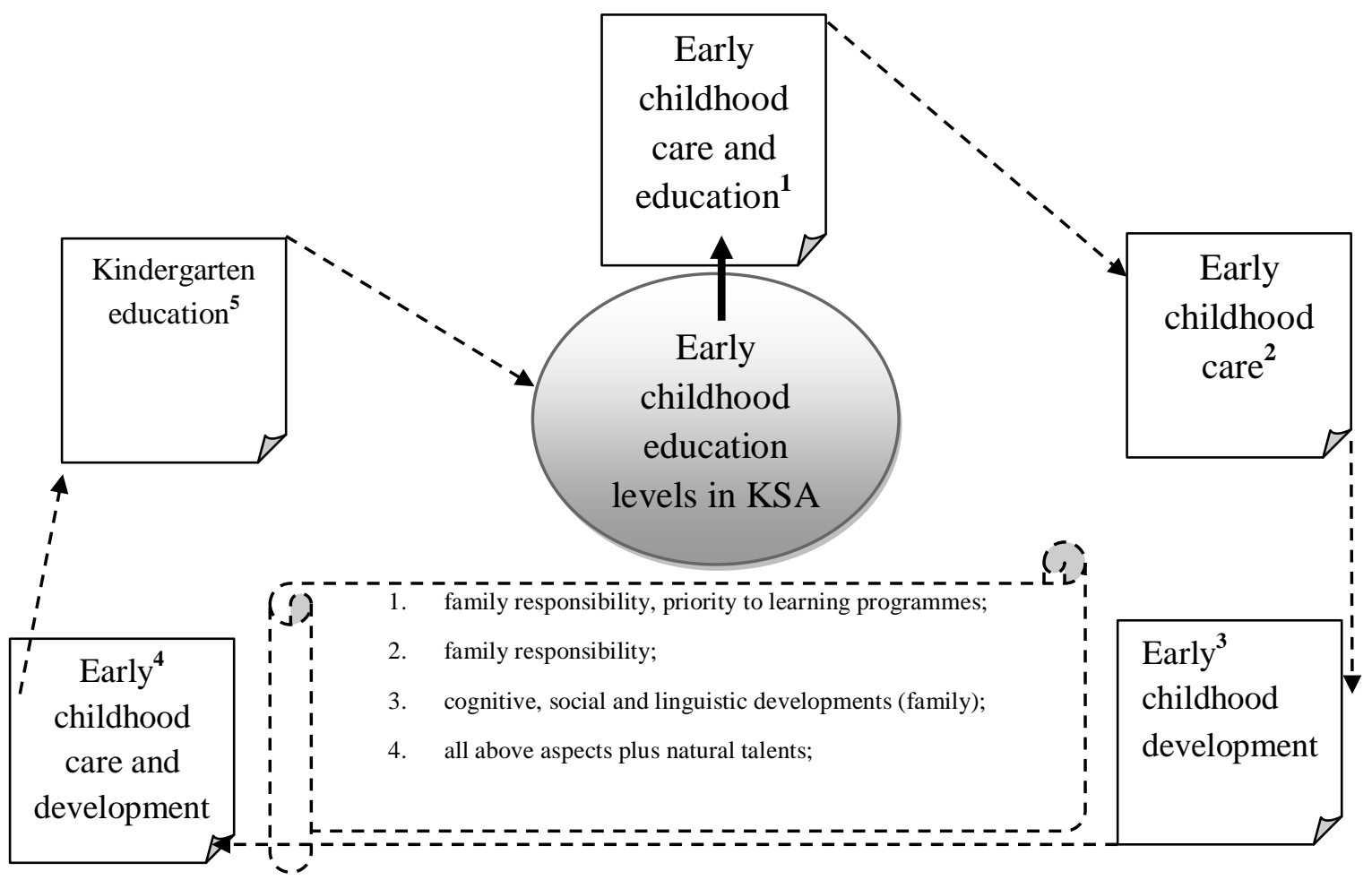

With reference to the above accounted four issues (language development, PLD, and EChE), previous researchers studied the pragmatic language development association with preschool, some proposed the theory that there's no effect or relationship between the two, while some thought that preschool had minimal or no effect on PLD. In fact, they claimed that other factors are contributing to this process; that is, parents, environmental factors, and culture or society.

For instance, Deal ${ }^{20}$ conducted a study trying to understand the relationship between pragmatic language skills and chronically disruptive classroom behaviour. This research was concluded with that there is a relationship between pragmatic language skills and functioning behaviour.

Boje $^{21}$ conducted a study raising the issue of approaching pragmatics from different perspectives and the need for a unified approach that mostly considers pragmatics from a socio-constructivism perspective. The study was concluded with a clinical perspective of what a speech pathologist dealing with preschoolers should consider.

Conway ${ }^{22}$ conducted a study emphasizing the importance of preschool enrollment and its relationship to school enrollment readiness. This study was concluded with that the children who were enrolled in preschool education showed readiness to kindergarten school enrollment compared to those who were not enrolled in preschool education and did not show readiness.

Fish $^{23}$ pre-assumed in his study that the positive impact of early childhood education is an unarguable issue. Have assumed thin, he then attempted on his study to propose a new method that would empower such gained skills in the early childhood education, mainly in reading and mathematics through intensity education. The study was concluded with that only few relationships were observed between experiencing education intensity and education with or without prekindergarten attendance.

Ortiz $^{24}$ conducted a study searching if language development in general is associated with other affecting factors including "ethnicity, cultural practice", and more importantly "family structure". The study is ended with that an early connect was actually found among such variables.

Ezrine $^{25}$ concluded his study about the relationship between language skills and the development of executive functions in a normative preschool population with a positive answer ascertaining and underscoring as the same time the importance of preschool education due to its relationship to executive functions.

Ljubica, Fekonja, Bajc, and Kranjc ${ }^{26}$ concluded their study about the effect of preschool and quality of home literary environment on the child's language development with that early childhood education has positive 
effects on children's language development, some differences between very early enrollment and early enrollment were observed in favour of the very early preschool enrollers.

Williams ${ }^{27}$ compared language development skills including social-cognitive skills (joint attention and imitation) and word learning constraints (fast-mapping) between children with typical language development and children with autism spectrum disorder ASD. The results indicated the absence of any differences except that the latter ones showed less accurate utilized words and social-cognitive skills.

Tare $^{28}$ investigated the development of pragmatic language on bilingual preschoolers and it was found that pragmatic differentiation [acquiring two pragmatic systems of two languages] "is not an all-or-none ability, but one which has component skills that develop over the preschool years, this protracted development is also related to metacognitive abilities which emerge during the preschool year".

Based on Tare' $\mathrm{s}^{28}$ finding regarding the correlation of PLD and EChE, it is assumed in this paper that pragmatic language development is related to early childhood education. It is also proposed that children who were enrolled to EChE will pragmatically perform better than those who were not enrolled. These hypotheses are investigated through two Saudi female groups: preschoolers and non-preschoolers. Thus, detailed methodology for this paper is discussed below.

\section{II.1. Participants}

\section{Method}

The population of the current paper was Saudi female $1^{\text {st }}$ grade pupils who were enrolled in early childhood education or preschool education and who were not. Besides, the population of this study focused only on typical developing children in terms of all development levels be it: physical, cognitive, social, emotional or linguistic level.

The researchers followed the convenience sampling method in this paper where in it was necessary to find two Saudi female groups who were enrolled in EChE and who were not so that correlation between the two variables could be found.

The setting of this study was at a public female elementary school by the name 158; the school is located in the North of Riyadh, Riyadh, KSA (Alghadeer district), which has pupils with an average economical status. The elementary school (158) has two first grade classrooms, each class has 25 students; a total of 30 normal healthy students were chosen, 15 who were enrolled in a preschool, and 15 who weren't. Finally, this study was conducted at the end of the academic year 2011-2012.

The following table demonstrates the characteristics of the selected sample in this paper. In this table, it is shown that all the conveniently selected participants share nearly all features (number of participants, gender, age range, school level and grade, diagnosis, native language, dialect, variety, ethnicity, nationality, whether is able to use or is learning other languages rather than Arabic language), except in the selection criterion where (group A) should be from those who were enrolled in EChE and (group B) should be from those who were not enrolled in EChE.

\begin{tabular}{|c|c|c|}
\hline Variable & Group (A) characteristics & Group (B) characteristics \\
\hline No. of participants & 15 & 15 \\
\hline Gender & Female & Female \\
\hline Age range & $6-7$ & $6-7$ \\
\hline School level & Elementary (1 grade) & Elementary (1 grade) \\
\hline Diagnosis & Typical development & Typical development \\
\hline Native language & Arabic & Arabic \\
\hline Dialect & Saudi Arabic Language & Saudi Arabic Language \\
\hline Variety & Najd and Hejaz & Najd and Hejaz \\
\hline Ethnicity & Islam & Islam \\
\hline Nationality & Saudis & Saudis \\
\hline Selection criterion & Preschoolers & Non-preschoolers \\
\hline Other languages & No & No \\
\hline
\end{tabular}

\section{II.II. Measures}

Pragmatics can be evaluated using different assessment tools. The researchers used the Arabic version of the TOPL-2. The TOPL-2 is a formal assessment tool that was constructed by Diana Phelps-Terasaki and Trisha Phelps-Gunn ${ }^{29}$. The A-TOPL is a version translated and tested for its usability in Arabic by Alduais, Shoeib, Al-Hammadi, Almalki ${ }^{30}$; Alduais, Shoeib, Al-Hammadi, Almalki, Alenezi ${ }^{31}$.

According to [30, 31], three types of reliability and five types of validity were achieved in the ATOPL. In details, all inter-rater, test-retest and internal reliability were measured and the calculated scores were: $97.98, .73$, and .90 , respectively. For validity, face validity, content, concurrent, convergent, and discriminant validity were measured and the calculated scores were: high, good, .24 (low), $.42 \&-.42$, and .50 respectively. 
It should be noted; however, that the A-TOPL is identical to the TOPL-2 in terms of consisting 43 items that measure PLA of children on the age range 6-18 (items 1-17 for ages 6-8) and (items 1-43 for ages 818). Besides, the test also consists of 19 items under the purpose of pragmatic evaluation (the researchers did neither include the results of these 19 items nor they include the result of the 43 items. Instead only the results of 17 items are included in this study as the age range of all the participants is 6-7).

Furthermore, the test measures PLA in terms of three major components: situational component, discourse, and semantic component. Again, within each major component there are sub-components: physical context and audience for the first component, topic and purpose for the second component, and visual-gestural cues, abstractions, and pragmatic-evaluation for the third component.

The test also contains detailed guidelines for analysis which merely include: raw score, percentile rank, pragmatic language using index, descriptive rating, age equivalent, and grade equivalent.

Design

This paper has two principal objectives:

1. To see if the Saudi female preschoolers will achieve pragmatically better than the non-preschoolers in the A-TOPL.

2. To see if PLD is associated with EChE.

On the basis of the above two objectives, the current paper was designed. In other words, the correlational research approach was selected for achieving the second objective and the non-experiment quasiexperimental approach was selected to achieve the first objective of this paper. Above all, the main variables that would be discussed in this paper and with reference to the above two chosen research designs are:

1. Pragmatic language development PLD;

2. Early childhood education.

Yet, in the correlational design, these two variables could be depicted in a notional form as:

$\mathrm{R} \mathrm{X} \mathrm{O} \mathrm{r}^{+}$

$\mathrm{RX} \mathrm{O}^{-} \mathrm{r}^{-}$

where:

$\mathrm{R}=$ pragmatic language development PLD (variable 1: independent)

$\mathrm{O}=$ early childhood education EChE (variable 2: independent)

$\mathrm{X}=$ Arabic Test of Pragmatic Language ATOPL

$\mathrm{O}^{+}=$preschoolers

$\mathrm{O}^{-}=$non-preschooler

$\mathrm{r}=$ correlation coefficient

$\mathrm{r}^{+}=$presence of correlation between the two variables

$r=$ absence of correlation between the two variables

The first hypothesis could be also depicted as:

$\mathrm{H}_{\mathrm{o}}=\mathrm{r}=0$

$\mathrm{H}_{1}=\mathrm{r}<>0$

where:

$\mathrm{H}_{\mathrm{o}}=$ null hypothesis

$\mathrm{H}_{1}=$ alternative hypothesis

On the other hand, the same variables in the second chosen design can be depicted in a notional form also as:

$\mathrm{R}^{+} \mathrm{X} \mathrm{O}^{+}$

$\mathrm{R}^{-} \mathrm{X} \mathrm{O}^{-}$

where:

$\mathrm{R}=\mathrm{EChE}$ (the independent variable)

$\mathrm{O}=\mathrm{PLD}$ (the dependent variable)

$\mathrm{X}=$ the ATOPL (measurement tool)

$\mathrm{R}^{+}=$preschool enrollment

$\mathrm{R}^{-}=$preschool non-enrollment

$\mathrm{O}^{+}=$existence of effect of the independent variable on the dependent one

$\mathrm{O}^{-}=$non-existence of effect of the independent variable on the dependent one

\section{II.III. Procedures}

Data collection: A semi-parallel procedure was followed for selecting the participants in this paper; that is, they were selected based on being all on the $1^{\text {st }}$ grade at the time of conducting the study and yet representing preschool enrollers and non-preschooler enrollers. By nature, the A-TOPL and as a formal assessment tool, it results to qualitative data, though quantitative data is also possible and provided. Therefore, 
the ATOPL was administered on the two selected groups and required data regarding their pragmatic language ability was collected.

Authenticity: A formal request was given from the College of Applied and Medical Sciences to the school to grant permission to administer the TOPL-2 (the Arabic version) on its pupils. Besides, parents' agreement forms were distributed to the pupils to be signed, two days before the test was administered on them.

Test administration: The test was administered on first grade pupils only, because their performance and skills will not be enhanced by the affects of elementary school. The role of test administration was exchanged among the three last researchers as ordered in the first page of the paper.

Time and environment of test administration: The test was administered on one session and the time required to administer and score the test was 40 minutes for each pupil. The environment was made as comfortable as possible to make the child far from any either mental or physical distractions. It simply contained a comfortable chair, a table, and another chair for the test administrator.

Process performance: From the 17 questions, each question was read to the child, showing the related picture and then writing the answer. The scores were recorded after completing the test administration session. All the directions in relation to this issue were followed identically as those provided by the author of the original English version of the test ${ }^{29}$.

Scoring: For each correct and suitable answer and according to the provided list of possible correct and incorrect answers, a participant is given (1) score for the correct answer(s) and (0) score for the incorrect one(s).

Preliminary analysis steps: Following the guidelines provided by the author of the test, the raw score of each participant was first obtained by counting the correct and incorrect answers, converting the obtained raw score into the pragmatic language usage index, and then finding out the percentile rank. The last step was getting a descriptive rating for each, using again the pragmatic language usage index.

\section{Results}

The $17^{\text {th }}$ version of the Statistical Package for Social Sciences SPSS-17 was used to analyse the collected data of this paper. Both descriptive and inferential statistics were used in order to investigate the two proposed hypotheses of the current study. To remind ourselves of the two proposed hypotheses:

1. There are differences between preschoolers and non-preschoolers in terms of PLD;

2. PLD is associated and/or correlated with EChE.

The null hypotheses are:

1. There are no differences between preschoolers and non-preschoolers in terms of PLD;

2. PLD is not associated and/or correlated with EChE.

The two tables below show the used statistics, the tools used from each type, the purpose of using it, and the reason behind using each tool.

\begin{tabular}{|c|c|c|}
\hline \multicolumn{3}{|c|}{ TABLE 4: Descriptive statistics } \\
\hline Tool & Purpose & Reason \\
\hline Descriptives & Getting means and standard deviations & $\begin{array}{l}\text { Giving preliminary estimations about } \\
\text { the differences between the two groups }\end{array}$ \\
\hline Frequencies & $\begin{array}{l}\text { Getting two pie charts illustrating the two groups } \\
\text { achievement in the ATOPL descriptively }\end{array}$ & $\begin{array}{l}\text { Making it easy to know the differences } \\
\text { between the two groups }\end{array}$ \\
\hline Graphs & $\begin{array}{l}\text { Getting a doubled histogram comparing the results of } \\
\text { the two groups in different types of converted scores }\end{array}$ & $\begin{array}{l}\text { Giving more general description about } \\
\text { the differences between the two groups. }\end{array}$ \\
\hline
\end{tabular}

\begin{tabular}{|c|c|c|}
\hline \multicolumn{3}{|c|}{ TABLE 5: Inferential statistics } \\
\hline Tool & Purpose & Reason \\
\hline $\begin{array}{l}\text { Correlate: } \\
\text { Bivariate }\end{array}$ & $\begin{array}{l}\text { Getting the correlation coefficient and } \\
\text { degree of significance }\end{array}$ & $\begin{array}{l}\text { Deciding on whether there is a relationship or not } \\
\text { between the two tested variables }\end{array}$ \\
\hline $\begin{array}{l}\text { Graphs: } \\
\text { scatter-plot }\end{array}$ & $\begin{array}{l}\text { Seeing in clearer way the correlation } \\
\text { between the two tested variables }\end{array}$ & $\begin{array}{l}\text { Ascertaining the presence or absence of } \\
\text { relationship between the two tested variables }\end{array}$ \\
\hline
\end{tabular}

The table below shows the achievement of both preschoolers and non-preschoolers in the A-TOPL in means $\mathrm{M}$ and standard deviations SD. It can be seen that the means and the standard deviations of the two groups are tightly close to one another. In other words, in the first two rows, the mean for preschoolers group is (9.53) compared to the mean of the non-preschoolers which is (8.20). Again the standard deviations are also very close to one another as (2.29) for the former and (2.40) for the latter. Besides, the minimum achieved raw score in the A-TOPL is 6 for the preschoolers' group and 3 for the non-preschoolers' group. On the other hand, the maximum achieved raw score is 14 for the preschoolers' group and 11 for the non-preschoolers' group. It can be concluded that the difference between the two groups in terms of means and standard deviations is considerably little. 


\begin{tabular}{|c|c|c|c|c|c|}
\hline & $\mathrm{N}$ & Minimum & Maximum & Mean & $\mathrm{SD}$ \\
\hline Raw scores of preschoolers & 15 & 6.00 & 14.00 & 9.53 & 2.29 \\
\hline Raw scores of non-preschoolers & 15 & 3.00 & 11.00 & 8.20 & 2.40 \\
\hline Pragmatic Language Usage Index of Preschoolers & 15 & 96.00 & 123.00 & 106.80 & 7.94 \\
\hline Pragmatic Language Usage Index of Non-preschoolers & 15 & 80.00 & 112.00 & 101.87 & 8.69 \\
\hline
\end{tabular}

The figure below illustrates in two pie charts the descriptive rating of the preschoolers' group and the non-preschoolers' group. It is very clear that in both groups the greatest percentage is on the average level. Say it another way, in the first group only over $13 \%$ and the same percentage also have got the grades superior and above average. On the other hand, there is only less than $7 \%$ who got below average grade and over $93 \%$ have got the average grade compared to over $73 \%$ for the preschoolers' group. In summary, it can be claimed that there are little differences between the two groups as some grades which appeared in the preschoolers' group did not appear in the non-preschoolers' group, for instance, (superior and above average for the former, and below average for the latter).

FIGURES 3 \& 4: Descriptive rating on A-TOPL of preschoolers and non-preschoolers
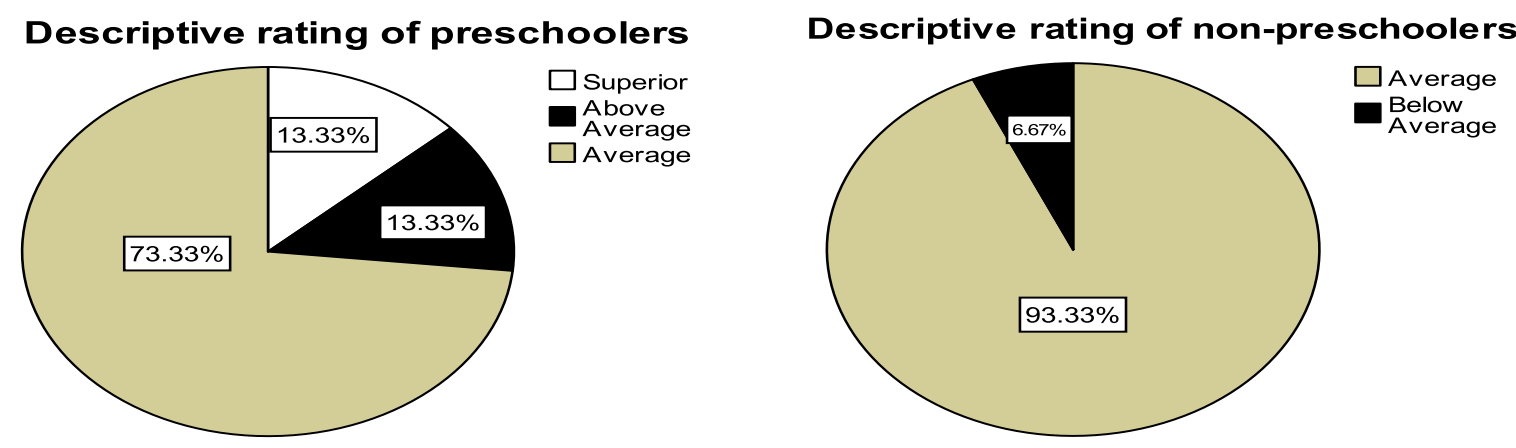

It has been mentioned in section 2 (Method) that the calculated raw scores achieved by the participants can be converted into different types of values using the index provided by the authors ${ }^{29}$ of the TOPL- 2 in the examiner's manual. The histogram below demonstrates these conversions under the purpose of giving a more general idea about the differences between the two groups in their achievement in the A-TOPL. In general, the columns in white represent the non-preschool enrollers' group and the columns in black represent the preschool enrollers' group. However, it can be observed that the differences between the two groups in all the provided values are not significant, though they exist.

FIGURE 5: Comparing the performance of preschoolers and non-preschoolers on A-TOPL

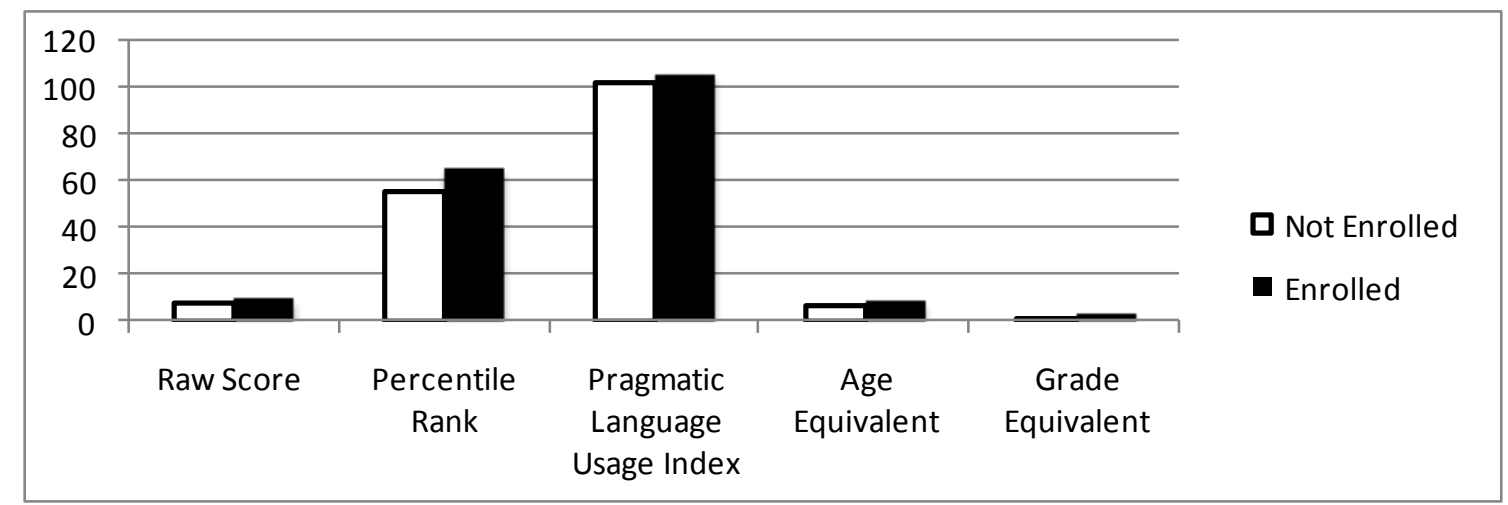

The table below presents the results of the correlation between the preschoolers' group and the nonpreschoolers' group using Pearson correlation coefficient (r). The converted raw scores' values for the two compared groups were converted into pragmatic language usage index PLUI and then correlated to see if PLD is associated with EChE. The first score (-.610) shows the correlation coefficient (r) which actually appears with the minus (-) mark which means the correlation between the two variables is negative. The second number 
represents the significance and it is here (.016), considerably greater than .05 which means that there is no statistically significant correlation between PLD and EChE.

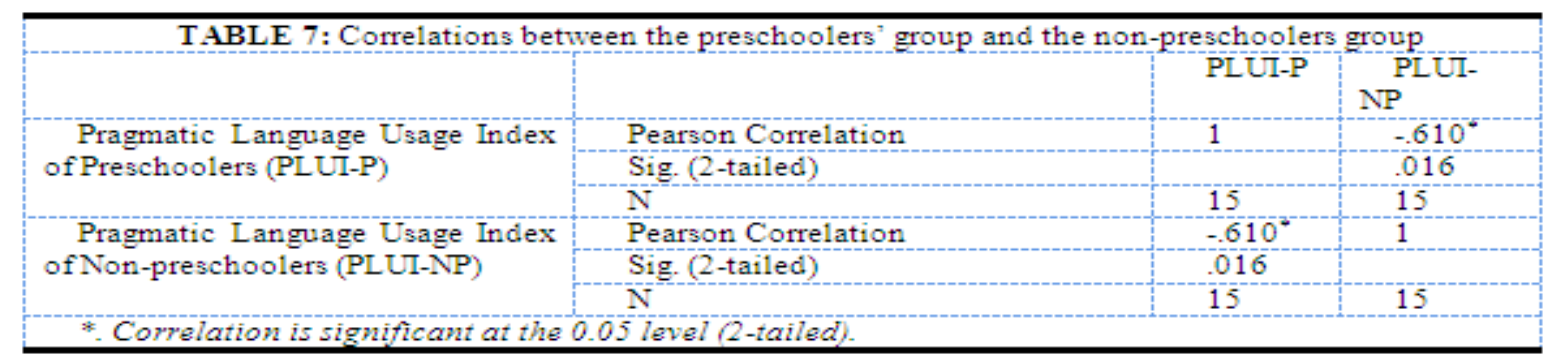

The scatter-plot below illustrates the direction and strength of relationship between the two investigated variables, namely: PLD and EChE. Basically, correlation in a scatter-plot can be either positive, negative, or zero as in the case of this paper. As it can be seen, it is very difficult to imagine or identify a line for the presented dots in this figure, so the correlation between the PLD variable and the EChE variable is zero.

FIGURE 6: Direction of the correlation between the two tested variables

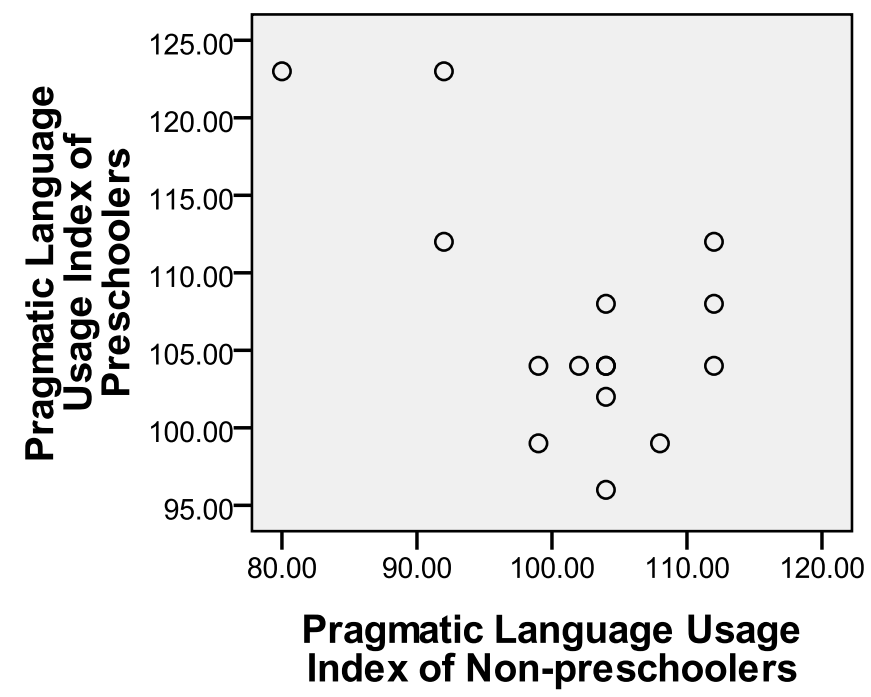

\section{Discussion}

With reference to the reviewed studies in section 1, most of them supported the claim that PLD and EChE are intricately and undoubtedly related to one another. These studies included but were not restricted to those conducted by $[12,20-26,28]$. For instance, Reyes and Lopez ${ }^{12}$ claimed that "children that attend high quality preschool programs do better cognitively, linguistically, and socially than those who do not attend preschool".

On the contrary, a few number of the reviewed studies supported the counterpart claim that either very little differences or no differences at all between preschoolers and non-preschoolers would exist. For instance, Williams $^{27}$ concluded her study with that observed correlations and differences between her two groups were actually insignificant in spite of the fact that they really minimally exist.

In the current study, the researchers claimed first that there are significant differences between children who were enrolled to preschool education and those who were not in terms of PLD. Second, they claimed that PLD must be associated with EChE. The statistical results and their interpretation in section 3, unfortunately, appeared exactly the opposite of the researchers' expectations. That is to say, the null hypotheses stating that there are no significant differences between preschoolers and non-preschoolers in PLD and PLD is not necessarily associated with EChE, have come true instead. Thus, the possible interpretations behind these reachable findings are mentioned in the implications of the study and the limitations of the study as well.

\section{Conclusions}

The results of this study were clearly contrary to initial expectations. The alternative hypotheses suggested that there will be statistically significant differences between Saudi female preschoolers and nonpreschoolers in terms of PLD achievement in the A-TOPL and also PLD must be necessarily correlated with 
EChE. Exactly the reverse happened - there were just little differences which are statistically insignificant between the preschoolers' group and the non-preschoolers' group in relation to PLD achievement, and the association between PLD and EChE was negative, insignificant statistically, and zero relation in the case of determining the direction of the relationship between the two investigated variables.

\section{Implications Of The Study}

This study has a number of implications which at the same time can be considered as possible interpretations for the reachable results in this study. The first implication is for academic researchers where in they should pay attention that two-groups non-experimental studies are not highly recommended as they do not usually lead to highly valid and reliable answers as happened in the case of this study. The second implication for the academic researchers also is that correlational research approach is really valuable, but when the researcher considers the issue that the greater the number the more valid and reliable answers for the raised questions in the study s/he will reach. The last implication is for education policy makers in KSA in particular and in the Arab World in general who are kindly required to fund a number of detailed projects investigating the benefits of early childhood education EChE at different aspects (linguistics, cognitive, and social).

\section{Limitations Of The Study}

Finally, this study has also a number of limitations which could be also considered as possible interpretations for the reachable results. The number one limitation is gender-bias; that is, the participating children from the population of preschoolers and non-preschoolers were only females, which makes it difficult to reach generalizable conclusions about the difference and also relationship between preschoolers and nonpreschoolers in terms of PLD achievement. One more limitation is the number of the participating children in relation to the selected research approaches specially the correlational one which requires preferably greater number of participants than those who participated in this study. Additionally, collected-data validity threat; that is, the participating children should have been either those who have completed the preschool education level and have not been enrolled yet in the elementary school level, or those who were about to finish the preschool education level. In this study, however, they were in the $1^{\text {st }}$ grade of the elementary school level. Last but not least, the proliferation strategy should have been used in this research in order to reach more reliable and valid results. That is to say, an additional informal measurement tool should have been used in addition to the formal measurement tool, namely, the Arabic versions of the TOPL-2.

\section{Acknowledgements}

Great thanks are due to the participating children from the elementary public school (158) in the North of Riyadh and for their parents as well who kindly agreed about the participation of their children in this study.

\section{References}

[1] Levine, Laura E., and Joyce A. Munsch. Child Development: An Active Learning Approach . Los Angelos, London, New Delhi, Singapore, Washington DC: SAGE Publications, Inc , 2011.

[2] Bartolotta, Theresa E., and Brain B. Shulman. "Child Development ." In Language Development: Foundations, Processes and Clinical Applications, by Brian B. Shulman and Nina C. Capone, 1-33. Boston, Toronto, London, Singapore : Jones and Bartlett Publishers, 2010.

[3] Bochner, Sandra, and Jane Jones. "Explanations for Language Development in Children." In Child Language Development: Learning to Talk, 3-13. Wiley, 2008.

[4] Brandone, Amanda C., Sara J. Salkind, Roberta Michnick Golinkoff, and Kathy Hirsh-pasek. "Language Development." In Children's Needs III: Understandign and addressing the developmental needs of children, edited by George G. Bear and Kathleen M. Minke, 499-514. Bathesda MD: National Association of School Psychologists, 2006.

[5] Saxton, Matthew. Child Language: Acquisition and Development. London: Sage Publications Ltd, 2010.

[6] Marasco, Kendra, Carol O’Rourke, Laura Riddle, Laura Sepka, and Vicki Weaver. "Pragmatic Language Assessment Guidelines: A Best Practice Document ECICMC Standards and Guidelines Speech Sub-Committee." SeeMyIEP Website . March 2004. http://seemyiep.com/wordpress/wp-content/uploads/2012/10/New-York-Pragmatic-Language-Assessment-Guidelines.pdf (accessed October 30, 2012).

[7] Alduais, Ahmed Mohammed Saleh, Fayza Saleh Al-Hammadi, Rasha AbdulRahman Shoeib, Khalid Hassan Almalki, and Farah Hameid Alenezi. "Use of an Arabic-language Version of TOPL-2 to Identify Typical and Atypical Manifestations of Pragmatic Language Impairment in Individuals with Developmental Dysphasia." Journal of Humanities and Social Science (JHSS) 3, no. 1 (2012): 11-22.

[8] Alduais, Ahmed Mohammed. The Use of Two Pragmatic Language Tests to Identify Typical and Atypical Manifestations of PLI: A Large-scale Study on Saudi Children and Adolescents with Developmental Dysphasia. Unpublished MA thesis, King Saud University (KSU), Riyadh, Saudi Arabia, 2013.

[9] Farrell, Beloff, and Lilia DiBello. "Early Childhood Education." In Encyclopedia of the Social and Cultural Foundations of Education, edited by Eugene F. Provenzo and Asterie Baker Provenzo. London: Sage Publications Ltd, 2009.

[10] Polnick, Barbara. "Early Childhood Education and Gender ." In Encyclopedia of Diversity in Education , by James A. Banks. Washington: SAGE Publications, 2012.

[11] Sullivan, Larry E. The SAGE Glossary of the Social and Behavioral Sciences. London: SAGE Publications Inc., 2009. 


\section{Investigating the Relationship between Pragmatic Language Development and Early Childhood}

[12] Reyes, Belinda, and Elias S Lopez. " Trends in Childcare and Preschool Enrollment Among Latino Children in California ." The Wealth Research Organization $\quad$ Website $\quad 2009$. http://wealthresearch.org/Reports/WRO_2009_Preschool\%20Research\%20Brief.pdf (accessed October 20, 2012).

[13] Barnett, W Steven. "Preschool Education and Its Lasting Effects: Research and Policy Implications." National Institute for Early Education Research Website. September 2008. http://nieer.org/resources/research/PreschoolLastingEffects.pdf (accessed October 21, 2012).

[14] Anderson, Laurie M., et al. "The Effectiveness of Early Childhood Development Programs." American Journal of Preventive Medicine 24, no. 35 (2003): 32-46.

[15] Oppenheim, Jerrold, and Theo Macgregor. "THE ECONOMICS OF EDUCATION: PUBLIC BENEFITS OF HIGH-QUALITY PRESCHOOL EDUCATION FOR LOW-INCOME CHILDREN." Democracy and Regulation Website . October 30, 2002. http://www.democracyandregulation.com/detail.cfm?artid=37 (accessed October 22, 2012).

[16] UNESCO. "World Data on Education: Saudi Arabia." http://www.ibe.unesco.org/fileadmin/user_upload/Publications/WDE/2010/pdf-versions/Kenya.pdf (accessed October 22, 2012).

[17] Alshaer, Abdulrahman I. "Education for all programmes in the Kingdom of Saudi Arabia: Background paper prepared for the Education for All Global Monitoring Report 2008 Education for All by 2015: will we make it?" UNESCO Website. 2007. http://unesdoc.unesco.org/images/0015/001554/155498e.pdf (accessed October 21, 2012).

[18] Rugh, William A. "EDUCATION IN SAUDI ARABIA: CHOICES AND CONSTRAINTS." Middle East Policy IX, no. 2 (2002): 40-55.

[19] Ministry-of-Education. "Suammary Statistics on General Education in K.S.A. Academic Year 2010/2011." Ministry of Education Website . 2011. http://www.moe.gov.sa/Pages/stats31-32.aspx (accessed October 31, 2012).

[20] Sara B. Deal. The relationship between pragmatic language skills and behavior. United States -- Minnesota: Walden University; 2009.

[21] Noreen Susan Boje. Constructing clinical judgments about preschool pragmatic language skills: An action research study. United States -- New York: University of Rochester; 2009.

[22] Donna M. Conway. The relationship between preschool programming and school readiness for rural children entering kindergarten. United States -- Minnesota: Walden University; 2010.

[23] Reva M. Fish. Relationship between education intensity in kindergarten and grade 1 and the academic benefits of attending preschool. United States -- New York: State University of New York at Buffalo; 2007.

[24] Eduardo Aquiles Ortiz. The influence of family structure and the role of siblings on early language development of Latino pre school children. United States -- Utah: Utah State University; 2009.

[25] Greer Alexander Ezrine. Effects of language on the development of executive functions in preschool children. United States -Georgia: Georgia State University; 2010.

[26] Ljubica MU, Fekonja U, Bajc K, Kranjc S. The Effect of Preschool and Quality of Home Literacy Environment on the Child's Language Development. Studia Psychologica 2006;48(2):157-173.

[27] Amie Williams. Language development in preschool children with autism spectrum disorders: Investigating fast-mapping abilities and utilization of word learning constraints. United States -- Alabama: The University of Alabama; 2009.

[28] Medha P. Tare. The development of pragmatic differentiation skills in preschool-aged bilingual children. United States -- Michigan: University of Michigan; 2008.

[29] Phelps-Terasaki, D., \& Phelps-Gunn, T. TOPL-2: Test of Pragmatic Language: Examiner's Manual. 2nd Edition . Austin, Texas: Pro-ed, 2007.

[30] Alduais, Ahmed Mohammed S., Rasha Abdulrahman Mohammed Shoeib, Fayza Saleh Al-Hammadi, and Khaldi Hassan Al-Malki. "Testing the Usability of an Arabic Version of TOPL-2 in Measuring Pragmatic Language Impairment in Children and Adolescents with Developmental Dysphasia." International Journal of Linguistics (IJL) 3, no. 2 (2012): 193-214.

[31] Alduais, Ahmed Mohammed S., Rasha Abdulrahman Mohammed Shoeib, Fayza Saleh Al-Hammadi, Khaldi Hassan Al-Malki, and Farah Hameid Alenezi. "Measuring Pragmatic Language in Children with Developmental Dysphasia: Comparing Results of Arabic Versions of TOPL-2 and CELF-4 (PP and ORS Subtests)." International Journal of Linguistics (IJL) 4, no. 2 (2012): $475-494$. 